\title{
EFFECT OF GRAPE SEED EXTRACT ON REMINERALIZATION OF ARTIFICIAL CARIES: AN IN-VITRO STUDY
}

\section{RUBEL M*, PRASHANT GM, NAVEEN KUMAR PG, SUSHANTH VH, MOHAMED IMRANULLA, IPSHITA POTLIA, SWATI MALLICK}

Department of Public Health Dentistry, College of Dental Sciences, Davangere, Karnataka, India. Email: rubelruby@yahoo.com Received: 31 May 2016, Revised and Accepted: 08 June 2016

\section{ABSTRACT}

Objective: Grape seeds are gaining more importance because the "Proanthocyanidins" present in them have excellent anticaries, remineralizing, and antibacterial properties. Although many preventive measures have been tried, dental caries remains one of the most prevalent diseases in humans. The ultimate goal of any intervention is the preservation of tooth structure, prevention of lesion progression and inducing remineralization. The present in-vitro study was done to investigate the effect of grape seed extract (GSE) on artificial enamel caries in human teeth.

Methods: A total of 50 sound premolars extracted from patients undergoing orthodontic treatment were used in the study. The teeth were cleaned and were immersed in a demineralizing solution for $96 \mathrm{hrs}$ at $37^{\circ} \mathrm{C}$ and $50 \%$ relative humidity to create artificial lesions. The samples were randomly divided into two groups of 25 each. Half of the samples were immersed in the GSE solution (test) and the other half in saline (control), respectively, for 8 days. The samples were measured by microhardness tester to obtain values in Vickers hardness scale. Data were entered into Microsoft Excel and were analyzed using independent t-test for inter-group comparison and paired t-test for intra-group comparison using SPSS version 21.

Results: The mean \pm SD microhardness values after remineralization for the test and control groups were $357.56 \pm 5.53$ and $337.60 \pm 6.38$. GSE group significantly increased the microhardness of the lesions $(\mathrm{p} \leq 0.001)$.

Conclusion: GSE is a potential remineralizing agent and can be used to prevent progression of dental caries.

Keywords: Grape seed extract, Remineralization, Dental caries.

(C) 2016 The Authors. Published by Innovare Academic Sciences Pvt Ltd. This is an open access article under the CC BY license (http://creativecommons. org/licenses/by/4. 0/) DOI: http://dx.doi.org/10.22159/ajpcr.2016.v9i5.13175

\section{INTRODUCTION}

Natural products have long been used in folk medicine and are promising sources for novel therapeutic agents, especially in treating oral diseases such as dental caries [1]. Although current preventive measures, including the administration of fluoride and broad-spectrum antimicrobials, along with the reduction of sucrose intake and effective oral hygiene habits, have been demonstrated to decrease caries prevalence, dental caries remains one of the most prevalent diseases in humans [2]. Dental caries is initiated by demineralization of the tooth surface through acid production from sugar by plaque biofilm. Streptococcus mutans is considered the principal cariogenic pathogen and plays a decisive role in the development of dental caries.

Although the use of antimicrobial agents, such as chlorhexidine or sodium fluoride, limit the growth and biofilm formation of cariogenic microorganisms, these conventional chemical antimicrobial agents have demonstrated some limitations and have not been recommended for regular caries prevention. Recently, much attention has been focused on plant-derived natural antimicrobial compounds, with potential use as alternatives to the common chemicals used for caries prevention [2].

Polyphenolic compounds (polyphenols) are secondary metabolites of plants. The consumption of polyphenol-rich foods or beverages has been reported to benefit oral health with antigingivitis, antimicrobial, antiplaque, and anticaries properties. Among the various fruits, grape seed extract (GSE) derived from the seeds of Vitis vinifera, is rich in polyphenolic compounds and consists free monomeric flavanols, i.e., the proanthocyanidins (PAs). Examples of PAs contained in GSE are catechin, epicatechin, and epicatechin-3-0-gallate, which are the structural building blocks [1-3].

PAs have remarkable dentine-specific protective effects by decreasing biodegradation rates and enhancing the mechanical properties of the organic matrix. PAs have been reported to strengthen collagen-based tissues by increasing collagen cross-links. There is evidence to prove that PA increases collagen synthesis and accelerates the conversion of soluble collagen to insoluble collagen [3].

It has been shown that GSE positively affects the remineralization process of root caries since collagen can serve as a substrate for apatite formation; the present study was designed to assess whether GSE, mainly consisting of PA, can effectively influence the remineralization of artificial caries in human teeth.

\section{Objective}

The present in-vitro study was done to investigate the effect of GSE on artificial enamel caries in human teeth.

\section{METHODS}

Study design

Randomized controlled trial.

\section{Sample size estimation}

Sample size was estimated by the following formula (based on the previous studies) [1]:

$\mathrm{N}=\frac{\mathrm{Z}^{2} \times \mathrm{SD}^{2}}{\mathrm{~L}^{2}}=25$ samples in each group.

Where, $\mathrm{N}$ is number, $\mathrm{Z}$ is $1.96(1-\alpha)$, $\mathrm{SD}$ is standard deviation, and $\mathrm{L}$ is an allowable error.

\section{Grape seed extract}

The GSE used in the present study was purchased from Pharmacon Gignos Pvt., Ltd., Bengaluru. It consisted of $97.8 \%$ PA, and the fluoride content was $<0.01 \mathrm{ppm}$ according to data provided by the manufacturer. The PA in the GSE is composed mainly of monomers (Catechins). A 6.5\% 
$(\mathrm{w} / \mathrm{v})$ solution in phosphate buffer $\left(0.025 \mathrm{M} \mathrm{KH}_{2} \mathrm{PO}_{4}, \mathrm{pH} 7.4\right)$ was used in this study which was prepared in the Department of Pharmacology. GSE solution was prepared from the same lot of extract.

\section{Specimen preparation}

A total of 25 extracted sound human premolars extracted for the orthodontic purpose were selected. They were thoroughly cleaned under tap water manually to ensure all the organic debris are removed and stored in $0.5 \%$ chloramine solution for $24 \mathrm{hrs}$ and then immersed in distilled water. The surfaces of the teeth were covered with an acid-resistant nail varnish. The teeth were stored at $4^{\circ} \mathrm{C}$ before use (according to ISO/TC 11405).

\section{Lesion formation and remineralization test}

The teeth were rinsed thoroughly with deionized water and then placed in a demineralizing solution $\left(2.2 \mathrm{mM}\right.$ of $\mathrm{CaCl}_{2} .2 \mathrm{H}_{2} \mathrm{O}, 2.2 \mathrm{mM}$ of $\mathrm{KH}_{2} \mathrm{PO}_{2}$ $45 \mathrm{mM}$ of acetate, $\mathrm{pH}=4.6$ ) for $96 \mathrm{hrs}$ at $37^{\circ} \mathrm{C}$ and $50 \%$ relative humidity to create lesions. Subsequently, the fragments were rinsed thoroughly with deionized water. The demineralized teeth were randomly divided into two groups by assistant scribe. One of the sections was immersed in saline, and another section was immersed in GSE solution $(6.5 \% \mathrm{w} / \mathrm{v})$ in phosphate buffer ( $3.4 \mathrm{~g}$ of $\mathrm{KH}_{2} \mathrm{PO}_{4}, 782 \mathrm{mg}$ of $\mathrm{NaOH}$ ) for 8 days. All solutions were freshly made on a daily basis before its use.

\section{Microhardness test}

To test microhardness, 25 test and 25 control samples were rinsed with deionized water and embedded in epoxy resin and sent to Bengaluru for microhardness evaluation. The embedded samples in epoxy resin were polished with 1- $\mu \mathrm{m} \mathrm{Al}_{2} \mathrm{O}_{3}$ felt papers. The surface Vickers hardness numbers (VHN) of specimens were measured by a trained and calibrated technician of the institute using a Vickers hardness tester (HXD-1000TM, Taiming Optical Instrument Co., Shanghai, China) under a load of $50 \mathrm{~g}$ for 15 seconds. Each specimen received a series of five indentations, $100 \mu \mathrm{m}$ from each other on its surface. The test and control sections were measured at different time intervals: At baseline, after demineralization, and after remineralization. The average values for the test and control sections of each tooth were calculated. The final VHN for the groups were obtained and analyzed.

\section{Statistical analysis}

Data were entered in Microsoft Excel and the mean and SD for each data were calculated. Statistical analysis was done using SPSS software version 21. Independent t-test was used for inter-group comparison and paired t-test was used for intra-group comparison. The confidence interval was set at $95 \%$. $p \leq 0.05$ was considered significant.

\section{RESULTS}

Table 1 and Fig. 1 show mean microhardness values $( \pm$ SD) of two groups at various time intervals: At baseline, after demineralization, and after remineralization. Independent t-test revealed statistically highly significant difference $(p \leq 0.001)$ between the two groups after remineralization. No statistically significant difference was seen between the groups at baseline and after demineralization. GSE group showed increased microhardness than the saline group after remineralization.

Table 2 and Fig. 2 show mean microhardness values $( \pm S D)$ of the two groups after demineralization and after remineralization. Paired t-test revealed statistically highly significant difference $(p \leq 0.001)$ between the after demineralization and after remineralization in the GSE group with increased microhardness after remineralization. There was no statistically significant difference seen after demineralization and after remineralization in the saline group.

\section{DISCUSSION}

Potent anticaries properties have been attributed to hydrophilic fractions of natural extracts such as polyphenolic high molecular weight compounds such as PAs. PA found in GSE has demonstrated to inhibit the enzymatic activity of glycosyltransferase F-ATPase and amylase and
Table 1: Inter-group comparison of GSE and saline at different time intervals

\begin{tabular}{llll}
\hline Groups & \multicolumn{2}{l}{ Mean VHN \pm SD } \\
\cline { 2 - 4 } & Baseline & $\begin{array}{l}\text { After } \\
\text { demineralization }\end{array}$ & $\begin{array}{l}\text { After } \\
\text { remineralization }\end{array}$ \\
\hline Test-GSE & $381.11 \pm 5.54$ & $337.24 \pm 4.35$ & $357.56 \pm 5.53$ \\
Control-saline & $381.24 \pm 4.77$ & $337.10 \pm 4.40$ & $336.41 \pm 4.05$ \\
p & 0.604 & 0.071 & $0.000 * *$ \\
\hline
\end{tabular}

Test used: Independent t-test and ${ }^{* *} \mathrm{p} \leq 0.001$ highly significant, ${ }^{*} \mathrm{p} \leq 0.05$ significant. GSE: Grape seed extract, VHN: Vickers hardness numbers, SD: Standard deviation

Table 2: Intra-group comparison after demineralization and after remineralization between the two groups

\begin{tabular}{lll}
\hline Groups & Mean VHN \pm SD & \\
\cline { 2 - 3 } & Test-GSE & Control-saline \\
\hline After demineralization & $337.24 \pm 4.35$ & $337.10 \pm 4.40$ \\
After remineralization & $357.56 \pm 5.53$ & $336.41 \pm 4.05$ \\
$\mathrm{p}$ & $0.000^{* *}$ & 0.154 \\
\hline
\end{tabular}

Test used: Paired t-test and ${ }^{* *} \mathrm{p} \leq 0.001$ highly significant, ${ }^{*} \mathrm{p} \leq 0.05$ significant GSE: Grape seed extract, VHN: Vickers hardness numbers, SD: Standard deviation

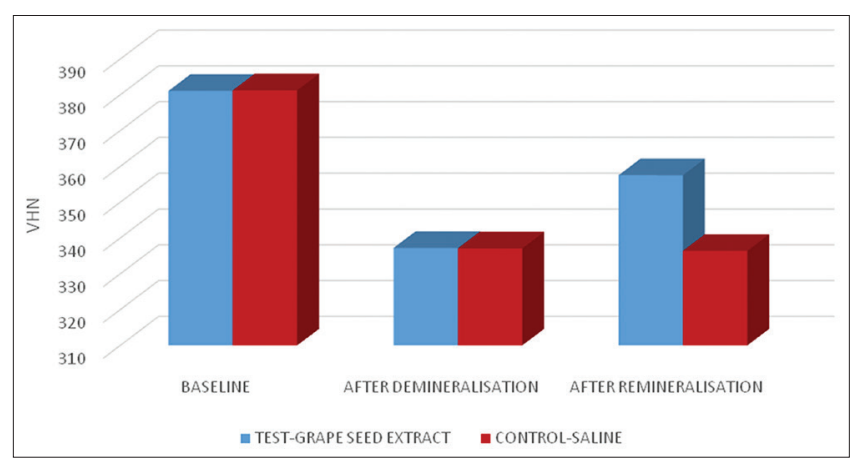

Fig. 1: Inter-group comparison, baseline and after demineralization $\mathbf{p}=\mathbf{0 . 6 0 4}$ and $\mathbf{p}=\mathbf{0 . 0 7 1}$ (non-significant), after remineralization $\mathrm{p}=\mathbf{0 . 0 0 1}$ (highly significant)

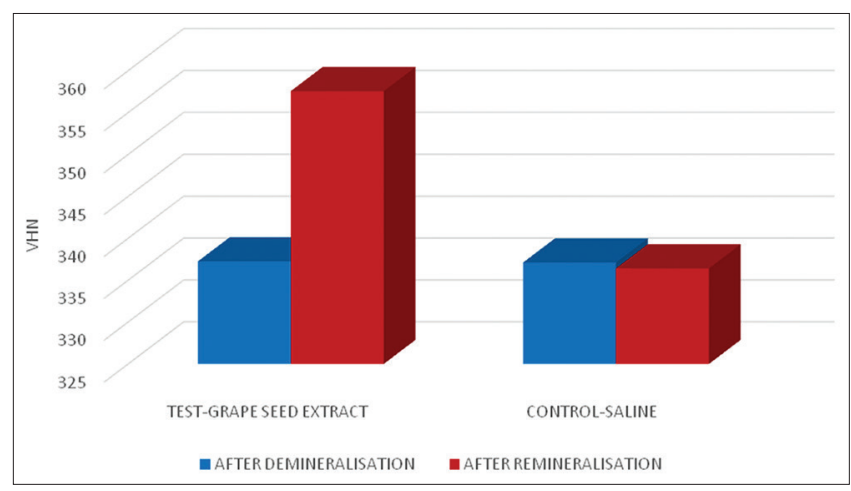

Fig. 2: Intra-group comparison, after demineralization $\mathbf{p}=\mathbf{0 . 1 5 4}$ (non-significant), after remineralization $\mathbf{p}=\mathbf{0 . 0 0 1}$ (highly significant)

prevent degradation of organic substances in the dentin matrix. Hence, this extract was used in the study [2].

The in-vitro $\mathrm{pH}$-cycling models are designed to simulate the dynamic variations in mineral saturation and $\mathrm{pH}$ associated with the natural 
caries process. To find the treatment's effect on existing enamel lesions, artificial caries lesions were produced according to Ten Cate and Duijsters. The pH-cycling procedure employed in this study exposed artificial caries lesions to repeated acid challenge followed by remineralization [2].

VHN values are indirect measurements of remineralization. Interestingly, variations in VHN were found at different time points, and differences were noted between the GSE and saline groups at same $\mathrm{pH}$ values, even under the same concentration levels, humidity, and temperature [3].

The results of the present study showed 20 VHN increase in the microhardness from 337.24 after demineralization to 357.56 after remineralization by GSE when compared to the saline group which further decreased by 1 VHN from 337.10 after demineralization to 336.41 after remineralization. Similar results were found in the studies conducted by Cheng et al. and Mirkarimi et al. on artificial enamel caries. They suggested that PAs and gallic acid present in the GSE are responsible for facilitating mineral deposition on enamel [1-3].

Berden Russo et al. demonstrated that GSE, as a collagen cross-linker, increased the stiffness of demineralized dentin in a study on changes in stiffness of demineralized dentin following the application of collagen cross-linkers. Furthermore, GSE has been shown to improve the ultimate tensile strength of demineralized dentin [4]. Al-Ammar et al. reported in his study on remineralization of artificial root caries lesions that the chemical modification of dentin matrix promoted by GSE resulted in increased bond strength [5]. In this context, GSE might contribute to mineral deposition on the superficial layer of the lesion by formation of insoluble complexes when mixed with bufferic phosphate solution; in addition, GSE might interact with proteins to induce cross-links by four different mechanisms: Covalent interaction, ionic interaction, hydrogen bonding interaction, and hydrophobic interaction.

Proline-rich proteins such as collagen have an extremely high affinity for PA-based components, forming a proline-PA complex. Although traditionally mature dental enamel is considered to be free of collagen, Acol et al. showed in his study done on enamel matrix degeneration that this is not the case and Type I collagen is found in enamel; however, the concentration of collagen in enamel was considerably lower as compared to that in dentin. Furthermore, Felszeghy et al. found that Type $\mathrm{X}$ collagen is one of the candidate molecules present in the enamel matrix, which might be involved in mineralization of enamel in his study, Type X collagen in human enamel development: A possible role in mineralization [6].

Based on data obtained in this in-vitro study, it may be proposed that GSE promotes the remineralization process of artificial carious lesions in the enamel. However, the taste of the GSE could not be assessed as its in-vitro study. Further in-vivo studies have to be done to assess the compatibility of GSE when incorporated in mouthwashes or gels.

\section{CONCLUSION}

Based on data obtained in this in-vitro study, we believe that GSE promotes the remineralization of artificial carious lesions.

The remineralization effect of GSE appears to be distinct. First, it contributes mineral deposition on the superficial layer of the lesion by forming insoluble complexes and combines with calcium to enhance remineralization. Second, GSE may interact with the organic portion of enamel through PA-collagen interaction, thereby stabilizing the exposed collagen matrix.
This solution might be considered an effective natural agent for noninvasive therapy of carious lesions as it is easily available and cost effective. As a promising cariostatic agent, GSE may be incorporated into toothpaste, gel, varnish, or mouth rinse. It can also be used as an adjuvant or alternative to topical application of fluoride and chlorhexidine.

\section{REFERENCES}

1. Mirkarimi M, Eskandarion S, Bargrizan M, Delazar A, Kharazifard MJ Remineralization of artificial caries in primary teeth by grape seed extract: An in vitro study 2013;7(4):206-10.

2. Xie $\mathrm{Q}$, Bedran-Russo $\mathrm{AK}, \mathrm{Wu} \mathrm{CD}$. In vitro remineralization effects of grape seed extract on artificial root caries. J Dent 2008;36(11):900-6.

3. Cheng L, Li J, Hao Y, Zhou X. Effect of compounds of Galla Chinensis on remineralization of enamel surface in vitro. Arch Oral Biol 2010;55(6):435-40.

4. Bedran-Russo AK, Pashley DH, Agee K, Drummond JL, Miescke KJ. Changes in stiffness of demineralized dentin following application of collagen crosslinkers. J Biomed Mater Res B Appl Biomater 2008;86(2):330-4.

5. Al-Ammar A, Drummond JL, Bedran-Russo AK. The use of collagen cross-linking agents to enhance dentin bond strength. J Biomed Mater Res B Appl Biomater 2009;91(1):419-24.

6. Felszeghy S, Holló K, Módis L, Lammi MJ. Type X collagen in human enamel development: A possible role in mineralization. Acta Odontol Scand 2000;58(4):171-6.

7. Benjamin S, Roshini S, Thomas SS, Nainan MT. Grape seed extract as a potential remineralising agent: A comparative in vitro study. J Cont Dent Pract 2012;13(4):425-30.

8. Tang CF, Fang M, Liu RR, Dou Q, Chai ZG, Xiao YH, et al. The role of grape seed extract in the remineralization of demineralized dentine: Micromorphological and physical analyses. Arch Oral Biol 2013;58(12):1769-76.

9. Liu R, Fang M, Xiao Y, Li F, Yu L, Zhao S, et al. The effect of transient proanthocyanidins preconditioning on the cross-linking and mechanical properties of demineralized dentin. J Mater Sci Mater Med 2011;22(11):2403-11.

10. Huang X, Cheng L, Exterkate RA, Liu M, Zhou X, Li J, et al. Effect of $\mathrm{pH}$ on Galla chinensis extract's stability and anti-caries properties in vitro. Arch Oral Biol 2012;57(8):1093-9.

11. Bagchi D, Bagchi M, Stohs SJ, Das DK, Ray SD, Kuszynski CA, et al. Free radicals and grape seed proanthocyanidin extract: Importance in human health and disease prevention. Toxicology 2000;148(2-3):187-97.

12. Green B, Yao X, Ganguly A, Xu C, Dusevich V, Walker MP, et al. Grape seed proanthocyanidins increase collagen biodegradation resistance in the dentin/adhesive interface when included in an adhesive. J Dent 2010;38(11):908-15.

13. Han B, Jaurequi J, Tang BW, Nimni ME. Proanthocyanidin: A natural crosslinking reagent for stabilizing collagen matrices. J Biomed Mater Res A 2003;65(1):118-24.

14. Castellan CS, Pereira PN, Grande RH, Bedran-Russo AK. Mechanical characterization of proanthocyanidin-dentin matrix interaction. Dent Mater 2010;26(10):968-73.

15. Gu LS, Kim J, Kim YK, Liu Y, Dickens SH, Pashley DH, et al. A chemical phosphorylation-inspired design for Type I collagen biomimetic remineralization. Dent Mater 2010;26(11):1077-89.

16. Friedman M, Jürgens HS. Effect of $\mathrm{pH}$ on the stability of plant phenolic compounds. J Agric Food Chem 2000;48(6):2101-10.

17. Almora-Barrios N, de Leeuw NH. A density functional theory study of the interaction of collagen peptides with hydroxyapatite surfaces. Langmuir 2010;26(18):14535-42.

18. Hagerman AE, Butler LG. The specificity of proanthocyanidin-protein interactions. J Biol Chem 1981;256(9):4494-7.

19. Açil Y, Mobasseri AE, Warnke PH, Terheyden H, Wiltfang J, Springer I. Detection of mature collagen in human dental enamel. Calcif Tissue Int 2005;76(2):121-6.

20. Ou KL, Chung RJ, Tsai FY, Liang PY, Huang SW, Chang SY. Effect of collagen on the mechanical properties of hydroxyapatite coatings. J Mech Behav Biomed Mater 2011;4(4):618-24. 